\title{
Optimization for Tribological Properties of Glass Fiber-Reinforced PTFE Composites with Grey Relational Analysis
}

\author{
Firojkhan Pathan, ${ }^{1}$ Hemant Gurav, ${ }^{2}$ and Sonam Gujrathi ${ }^{2}$ \\ ${ }^{1}$ BITS, Pilani, India \\ ${ }^{2}$ SRES-COE, Kopargaon, India \\ Correspondence should be addressed to Firojkhan Pathan; fzpathan@gmail.com
}

Received 1 April 2016; Revised 24 August 2016; Accepted 1 September 2016

Academic Editor: Te-Hua Fang

Copyright (C) 2016 Firojkhan Pathan et al. This is an open access article distributed under the Creative Commons Attribution License, which permits unrestricted use, distribution, and reproduction in any medium, provided the original work is properly cited.

\begin{abstract}
Most recent history shows that polytetrafluoroethylene (PTFE) is widely used as antifrictional materials in industry for wide speed range. A high antifriction property of PTFE makes it suitable for dry friction bearing. Main disadvantage of using PTFE is its high wear rate, so extensive research had been carried out to improve the wear resistance with addition of filler material. This study focuses on four input parameters load, sliding speed, sliding distance, and percentage of glass fiber as a filler material. Taguchi method was used for experimentation; each parameter is having 3 levels with L27 orthogonal array. Grey relational analysis is used to convert multiple response parameters, namely, wear and coefficient of friction, into single grey relation grade. The optimal input parameters were selected based on the $S / N$ ratio. It was observed that load $3 \mathrm{~kg}$, sliding speed $5.1836 \mathrm{~m} / \mathrm{s}$ ( $900 \mathrm{rpm})$, sliding distance $2 \mathrm{~km}$, and $15 \%$ of glass fiber are optimal input parameters for PTFE without significantly affecting the wear rate and coefficient of friction.
\end{abstract}

\section{Introduction}

As PTFE is having a very low coefficient of friction, it is considered as most slippery material in a dry friction bearing industry. Many researchers worked to improve the tribological properties of self-lubricating composites, and it is observed that a commonly used self-lubricating material having a very low coefficient of friction is polytetrafluoroethylene (PTFE) [1-4]. Unfilled PTFE is having a very high wear rate; however, the addition of PTFE to various polymeric materials gives low wear resistance and low coefficient of friction [5, 6]. PTFE is a lubricating self-lubricating material; addition of filler material to PTFE or Molybdenum Oxide $\left(\mathrm{MoS}_{2}\right)$ improved tribological characteristics. Addition of graphite fillers to PTFE material exhibited a very low wear rate and also the coefficient of friction [7]. PTFE filled with graphite resulted in much lower wear rate than when filled with $\mathrm{MoS}_{2}, \mathrm{ZrO}_{2}$, and $\mathrm{TiO}_{2}$ fillers [8]. To improve the tribological properties, bronze filler, carbon filler, and pure PTFE were used $[4,9]$.
Apart from the polymer composition, wear rate and coefficient of friction depend upon the counter face roughness and sliding speed. This dependence has been extensively studied by many researchers. Effect of sliding distance on the tribological behaviour of materials is having a substantial impact. Sliding wear on the composites is mostly dependent on the sliding distance because of its influence on physical properties [10]. Influence of soft and hard phases such as addition of bronze filler or addition of graphite fibers in a polymer matrix increases the self-lubricating and the loadcarrying properties of the matrix improving the tribological properties of the PTFE [11]. PTFE also has been used as filler material in different polymer composites to improve coefficient of friction and optimization process parameters are carried out [12].

There have been different components affecting the tribological properties of PTFE for the application of dry friction bearings used in sugar industry equipment, as we can see in fish-bone diagram in Figure 1. The input parameters which 


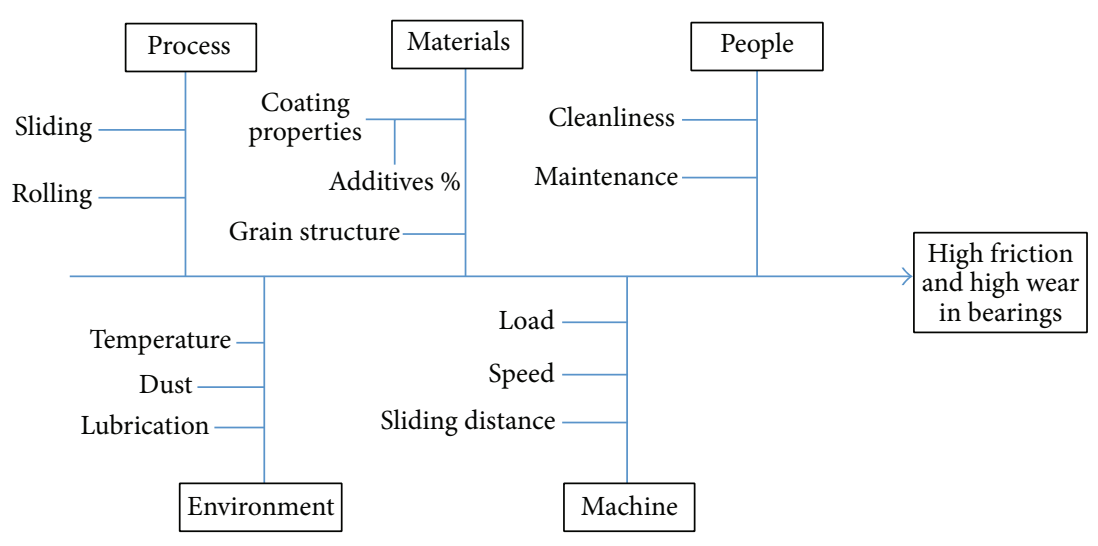

FIgURE 1: Fish-bone diagram.

are selected for this application are load, sliding distance, speed, and amount of percentage of filler material. To obtain the optimum combination of the above input parameters, we used design of experiments by Taguchi method. Also the study was carried out to obtain the optimum mixture of PTFE with glass fiber which would result in a better coefficient of friction along with minimum wear rate. Further GreyTaguchi approach is used to convert a multiresponse problem into a single one using weighting factors of grey relational analysis. Lastly, validation of the result was carried out by actual experimentation.

\section{Design of Experiment by Taguchi Method}

The purpose of the design of experiments was to investigate the tribological behaviour of the composites for different test conditions. Since the tests were performed under ambient conditions at a variable load (contact pressure), sliding speed, and sliding distance, we have carried out test on the pinon-disc apparatus. Experimentation is performed for the 3 different factors, namely, load $(A)$, speed $(B)$, and sliding distance $(C)$, on mixtures of PTFE with $\% \mathrm{GF}(D)$. These input parameters are considered as the main design factor. Each factor was subdivided into three levels as shown in Table 1. From the consideration of these experimental conditions, a predesigned orthogonal array, called L27 $\left(3^{4}\right)$, developed by Taguchi was applied to this study. An orthogonal array is used in this study which is listed in Table 2 where test conditions and test parameters are represented by rows and columns, respectively [12-14].

In sugar industries, dry friction bearings are regularly used; the operating conditions for the bearing show the range of load 1-3 kg, sliding distance $0-7000 \mathrm{~m}$, and speed 0$1000 \mathrm{rpm}$. As the literature suggests the increase in glass fiber percentage increases the coefficient of friction the following levels for input parameters were selected.

Pin-on-disc instrument is used to determine the two output responses, namely, wear and coefficient of friction (COF); both output responses are having cost criteria; that is, lower value is desirable.

Also optimal parameter settings for single performance characteristics could be established by conventional Taguchi
TABLE 1: Design factors and their levels.

\begin{tabular}{lccc}
\hline Factors & \multicolumn{3}{c}{ Levels } \\
& 1 & 2 & 3 \\
\hline Load $(\mathrm{kg})(A)$ & 1 & 2 & 3 \\
Speed $(\mathrm{m} / \mathrm{s})(B)$ & 1.7278 & 3.4558 & 5.1836 \\
Sliding distance $(\mathrm{km})(C)$ & 2 & 4 & 6 \\
Mixture GF\% $(D)$ & 0 & 15 & 20 \\
\hline
\end{tabular}

TABLE 2: L27 orthogonal arrays designed by Taguchi method.

\begin{tabular}{|c|c|c|c|c|}
\hline S. number & $\begin{array}{c}\text { Load } \\
(\mathrm{kg})\end{array}$ & $\begin{array}{l}\text { Sliding speed } \\
(\mathrm{m} / \mathrm{s})\end{array}$ & $\begin{array}{l}\text { Sliding distance } \\
(\mathrm{km})\end{array}$ & $\%$ glass fiber \\
\hline 1 & 1 & 1.7278 & 2 & 0 \\
\hline 2 & 1 & 1.7278 & 4 & 15 \\
\hline 3 & 1 & 1.7278 & 6 & 20 \\
\hline 4 & 1 & 3.4558 & 2 & 15 \\
\hline 5 & 1 & 3.4558 & 4 & 20 \\
\hline 6 & 1 & 3.4558 & 6 & 0 \\
\hline 7 & 1 & 5.1836 & 2 & 20 \\
\hline 8 & 1 & 5.1836 & 4 & 0 \\
\hline 9 & 1 & 5.1836 & 6 & 15 \\
\hline 10 & 2 & 1.7278 & 2 & 15 \\
\hline 11 & 2 & 1.7278 & 4 & 20 \\
\hline 12 & 2 & 1.7278 & 6 & 0 \\
\hline 13 & 2 & 3.4558 & 2 & 20 \\
\hline 14 & 2 & 3.4558 & 4 & 0 \\
\hline 15 & 2 & 3.4558 & 6 & 15 \\
\hline 16 & 2 & 5.1836 & 2 & 0 \\
\hline 17 & 2 & 5.1836 & 4 & 15 \\
\hline 18 & 2 & 5.1836 & 6 & 20 \\
\hline 19 & 3 & 1.7278 & 2 & 20 \\
\hline 20 & 3 & 1.7278 & 4 & 0 \\
\hline 21 & 3 & 1.7278 & 6 & 15 \\
\hline 22 & 3 & 3.4558 & 2 & 0 \\
\hline 23 & 3 & 3.4558 & 4 & 15 \\
\hline 24 & 3 & 3.4558 & 6 & 20 \\
\hline 25 & 3 & 5.1836 & 2 & 15 \\
\hline 26 & 3 & 5.1836 & 4 & 20 \\
\hline 27 & 3 & 5.1836 & 6 & 0 \\
\hline
\end{tabular}


method. Grey relation method can be used to convert multivariant response into a single parameter response which can be analysed by signal-to-noise ratio to obtain optimal parameters $[15,16]$.

2.1. Grey Relational Analysis. Signal-to-noise ratio $(S / N)$ is a measure of variability of the input parameters corresponding to output performance. As the main aim of this study is to optimize two response parameters, there is possibility of getting the higher $S / N$ ratio for one performance characteristic which may exhibit a lower $S / N$ ratio for another characteristic. Grey relational analysis was found to be an efficient tool for analysing this kind of problem. It was used to find out the key factors of the system and their correlations. The key factors were identified by the input and output sequences [17-19].

The original input parameters which are having objective "the higher, the better" were normalized as follows [20]:

$$
x_{i}(k)=\frac{y_{i}(k)-\min y_{i}(k)}{\max y_{i}(k)-\min y_{i}(k)} .
$$

When the objective was "the lower, the better," the original sequence was normalized as follows:

$$
x_{i}(k)=\frac{\max y_{i}(k)-y_{i}(k)}{\max y_{i}(k)-\min y_{i}(k)} .
$$

$y_{i}(k)$ is the original output response sequence; $(k)$ is the sequence for comparison and $i=1,2, \ldots, m, k=1,2,3, \ldots, n$, with $m, n$ being total number of experiments and responses. $\min y_{i}(k)$ is the least value of $y_{i}(k)$ and $\max y_{i}(k)$ is the highest value of $y_{i}(k)$.

Here, $x_{i}(k)$ was the value after the grey relational generation. An ideal sequence was $x_{0}(k)$. The grey relational grade exhibits the relational degree between the experimental run sequences $\left[x_{0}(k)\right.$ and $\left.x_{i}(k), i=1,2, \ldots, m\right]$.

The grey relational coefficient $(k)$ could be calculated as

$$
\xi_{i}(k)=\frac{\Delta_{\min }-\varphi \Delta_{\max }}{\Delta_{o i}(k)-\varphi \Delta_{\max }},
$$

where

$$
\Delta_{o i}=\left|x_{o}(k)-x_{i}(k)\right|
$$

The difference of the absolute value between $x_{0}(k)$ and $x_{i}(k)$ gives absolute difference $\Delta_{o i} . \Delta_{\min }, \Delta_{\max }$ were the minimum and maximum values of the absolute differences $\left(\Delta_{o i}\right)$ of all comparing sequences. $\psi$ value ranges from 0 to 1 and to have better results bigger number of researchers used $\psi$ to be 0.5 .

After averaging the grey relational coefficients, the grey relational grade $\gamma_{o}$ was calculated. The higher value of grey relational grade was inspected to be the stronger relational degree between the ideal sequence $x_{0}(k)$ and the given sequence $x_{i}(k)$. The ideal sequence $x_{0}(k)$ was supposed to be the best process response in the experimental layout. In grey relational analysis, higher grade gives the best or optimal performance for given parameters.
2.2. Grey Relational Grade. Accordingly, while converting multiple grey relational grades, the value of weighting factor in COF and wear was equally important. When appropriate, weighting factor $\beta$ was used with the sequence values; the general form of grey relational grades became

$$
\gamma_{0}=\sum_{k=1}^{n} \xi_{i}(k) \beta \gamma_{i}, \quad \sum \beta=1 .
$$

In this work, values of weighting factors for different responses had been taken as $\mathrm{COF}=0.5$ and wear $=0.5$. However, for establishing optimal parameter settings for single performance characteristics conventional Taguchi method could be used effectively.

Since multiple performance characteristics with conflicting goals were present, Grey-Taguchi method was taken into consideration.

2.3. S/N Ratio. As we are using Taguchi method for designing experiments, the next step is to determine best output response from all available designs. Since the total number of experiments required for the above experiments is 81 , we have taken only 27 experiments by using Taguchi method. Hence to capture the variability of the results, signal-to-noise ratio was used to analyse the grey relational grade. The signalto-noise ratio for overall grey relational grade was calculated from (6) presented below. In grey relational method, the higher value shows the more important parameter than the lower value, and hence we are using $S / N$ formula for higher is better as given in

$$
S / N=-10 \times \log _{e}\left[\frac{1}{N_{i}} \sum_{u=1}^{N} \frac{1}{y_{u}^{2}}\right],
$$

where $i$ is experiment number, $u$ is trial number, and $N_{i}$ is number of trials for experiment $i$.

\section{Experimental Setup}

For investigating the dry sliding wear characteristics of the composite, a pin-on-disc test apparatus was used. The wear specimen (pin) of $10 \mathrm{~mm}$ diameter and $30 \mathrm{~mm}$ height was cut from samples of material. While performing test, the pressure was applied on pin which is rubbed against the rotating EN32 steel disc with hardness of $65 \mathrm{HRC}$.

Figure 2 shows a schematic view of pin-on-disc machine used for this work. As shown in the figure, the machine consists of steel disc, which is mounted on circular turn table. The turn table is mounted on a bearing housing which provides the unidirectional motion to the turn table. A holder which is attaching to the turn table holds the cylindrical pin firmly. The loading arm is supported in bearing arrangement to allow load to be applied to the specimen. Frictional force and wear are measured by digital display. Table 3 gives the specifications of pin-on-disc machine, pin specimen, and disc.

3.1. Material Manufacturing. Polytetrafluoroethylene with different set of glass fibers percentage is manufactured by 


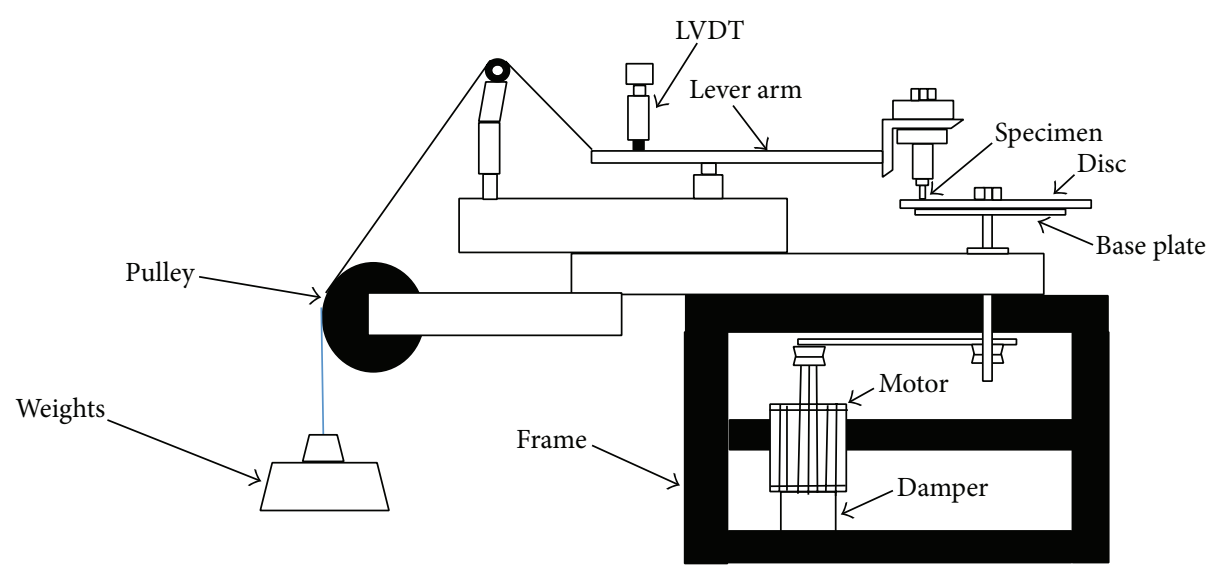

FIGURE 2: Schematic view of the pin-on-disc apparatus used in this study.

TABLE 3: Specification of pin-on-disc friction and wear monitor TR20.

\begin{tabular}{lc}
\hline Manufacturer & $\begin{array}{c}\text { Magnum Engineering Ltd., } \\
\text { Bangalore, India }\end{array}$ \\
\hline Pin diameter range & $\Phi 3 \mathrm{~mm}$ to $12 \mathrm{~mm}$ \\
Disc size & $\Phi 160 \mathrm{~mm} \times 8 \mathrm{~mm}$ thick \\
Wear track diameter & $\Phi 5 \mathrm{~mm}-70 \mathrm{~mm}$ \\
Sliding speed range & $0.25 \mathrm{~m} / \mathrm{s}-12 \mathrm{~m} / \mathrm{s}$ \\
Disc rotation speed & $100-3000 \mathrm{RPM}$ \\
Drive & KWDC motor, Constant Torque \\
Motor controller & Thyristor converter, with full motor \\
& protection \\
Frictional force & $0-250 \mathrm{~N}$, digital read-out with \\
Normal load & recorder output \\
Disc material & $0-250 \mathrm{~N}$ \\
Wear measurement range & EN-32 \\
Power & $\pm 2 \mathrm{~mm}$, digital read out with \\
\hline
\end{tabular}

compression sintering method. The pins are prepared with different set of glass fibers percentage and then fabricated for proper dimension on computer numerical control (CNC) lathe and grinder. Polishing of the pins is carried out at the end.

\section{Results and Discussions}

Different combinations of four input variables, namely, load $(A)$, speed $(B)$, sliding distance $(C)$, and mixtures of glass fiber $(D)$, were considered and eight output responses (output) were obtained. Therefore, the total number of experiments conducted was $27(i=27)$.

Following grey relational methods, experimental results were normalized in the range 0 to 1 . However, it was noted that, out of two responses shown in columns 1 and 2 of Table 4 , lower target values for COF and wear response are better; during normalization of data, target values of COF parameter were calculated using (2) as for both variables "lower is better." This normalized value of each response is shown in columns 3 and 4, and also differences of each sequence are shown in columns 5 and 6 .

Grey relation coefficients $\xi_{i}(k)$ were evaluated for each response by using (3). In order to determine the grey relational grades, (4) had been used. Considering appropriate weighting factors, the overall grey relational grade is calculated using (5). The grey relational coefficient of both wear and COF with their weightage factor is listed in Table 5.

4.1. S/N Ratio Analysis. The signal-to-noise ratio of each factor, mean signal-to-noise ratio, and ranking of each factor (according to effect) are listed in Table 6. The graphical representation of $S / N$ ratio for four factors, namely, load $(A)$, sliding speed $(B)$, sliding distance $(C)$, and \% glass fiber $(D)$, is shown in the main effect plot (Figure 2).

It had been observed from the plot that parameter $A$ (load) and \% GF were the most significant effect among the input parameters. The ideal process parameter combination corresponding to minimum wear and coefficient of friction was indicated by the maximum value for signal-to-noise ratio for each input parameter. Thus, from Table 6 and Figure 3, the optimum process parameter combination was found to be A3B3C1D2 also given in Table 4, Experiment number 25, that is, load $3 \mathrm{Kg}$, sliding speed $5.1836 \mathrm{~m} / \mathrm{s}$, sliding distance $2 \mathrm{~km}$, and glass fiber $15 \%$.

4.2. Confirmation Tests. After the ideal process parameter was selected from the $S / N$ ratio plot, the objective was to predict the result and verify it by actual experimentation. First, corresponding to optimum level of process parameters, the estimated $S / N$ ratio $(\widehat{\gamma}$,$) was evaluated using the following$ equation:

$$
\widehat{\gamma}=\gamma_{m}+\sum_{i=1}^{o}\left(\widehat{\gamma_{m}}-\gamma_{i}\right),
$$

where $\gamma_{m}$ is the total mean of $S / N$ ratio, $\gamma_{i}$ is the mean of $S / N$ ratio for optimum level, and $o$ is the number of the main 
Table 4: Experimental results and design of experiments using Taguchi.

\begin{tabular}{|c|c|c|c|c|c|c|}
\hline \multirow{2}{*}{ Experiment number } & \multicolumn{2}{|c|}{ Output response } & \multicolumn{2}{|c|}{ Normalized response } & \multirow[b]{2}{*}{$\begin{array}{c}\text { Wear } \\
\Delta_{01}\end{array}$} & \multirow[b]{2}{*}{$\begin{array}{c}\mathrm{COF} \\
\Delta_{02}\end{array}$} \\
\hline & $\begin{array}{c}\text { Wear } \\
\mu \mathrm{m}\end{array}$ & $\mathrm{COF}$ & $\begin{array}{c}\text { Wear } \\
X_{1}\end{array}$ & $\begin{array}{c}\mathrm{COF} \\
X_{2} \\
\end{array}$ & & \\
\hline 1 & 226.24 & 0.33 & 0.7364 & 0.4965 & 0.2636 & 0.5035 \\
\hline 2 & 80.13 & 0.3601 & 0.9146 & 0.3661 & 0.0854 & 0.6339 \\
\hline 3 & 47.66 & 0.4446 & 0.9542 & 0.0000 & 0.0458 & 1.0000 \\
\hline 4 & 48.4 & 0.362 & 0.9533 & 0.3579 & 0.0467 & 0.6421 \\
\hline 5 & 10.1 & 0.4265 & 1.0000 & 0.0784 & 0.0000 & 0.9216 \\
\hline 6 & 548.21 & 0.3528 & 0.3438 & 0.3977 & 0.6562 & 0.6023 \\
\hline 7 & 75.3 & 0.4183 & 0.9205 & 0.1140 & 0.0795 & 0.8860 \\
\hline 8 & 250.41 & 0.35 & 0.7069 & 0.4099 & 0.2931 & 0.5901 \\
\hline 9 & 81.9 & 0.3749 & 0.9124 & 0.3020 & 0.0876 & 0.6980 \\
\hline 10 & 32.96 & 0.2943 & 0.9721 & 0.6512 & 0.0279 & 0.3488 \\
\hline 11 & 40.27 & 0.3587 & 0.9632 & 0.3722 & 0.0368 & 0.6278 \\
\hline 12 & 830.12 & 0.27 & 0.0000 & 0.7565 & 1.0000 & 0.2435 \\
\hline 13 & 10.36 & 0.3506 & 0.9997 & 0.4073 & 0.0003 & 0.5927 \\
\hline 14 & 444.18 & 0.2465 & 0.4706 & 0.8583 & 0.5294 & 0.1417 \\
\hline 15 & 128.06 & 0.3072 & 0.8561 & 0.5953 & 0.1439 & 0.4047 \\
\hline 16 & 161.03 & 0.276 & 0.8159 & 0.7305 & 0.1841 & 0.2695 \\
\hline 17 & 48.6 & 0.2991 & 0.9530 & 0.6304 & 0.0470 & 0.3696 \\
\hline 18 & 11.91 & 0.3635 & 0.9978 & 0.3514 & 0.0022 & 0.6486 \\
\hline 19 & 30.51 & 0.2829 & 0.9751 & 0.7006 & 0.0249 & 0.2994 \\
\hline 20 & 725.06 & 0.2219 & 0.1281 & 0.9649 & 0.8719 & 0.0351 \\
\hline 21 & 261.31 & 0.2395 & 0.6937 & 0.8886 & 0.3063 & 0.1114 \\
\hline 22 & 345.77 & 0.2138 & 0.5907 & 1.0000 & 0.4093 & 0.0000 \\
\hline 23 & 85.73 & 0.2314 & 0.9078 & 0.9237 & 0.0922 & 0.0763 \\
\hline 24 & 94.65 & 0.2958 & 0.8969 & 0.6447 & 0.1031 & 0.3553 \\
\hline 25 & 12.91 & 0.2232 & 0.9966 & 0.9593 & 0.0034 & 0.0407 \\
\hline 26 & 19.01 & 0.2877 & 0.9891 & 0.6798 & 0.0109 & 0.3202 \\
\hline 27 & 472.97 & 0.2267 & 0.4355 & 0.9441 & 0.5645 & 0.0559 \\
\hline
\end{tabular}

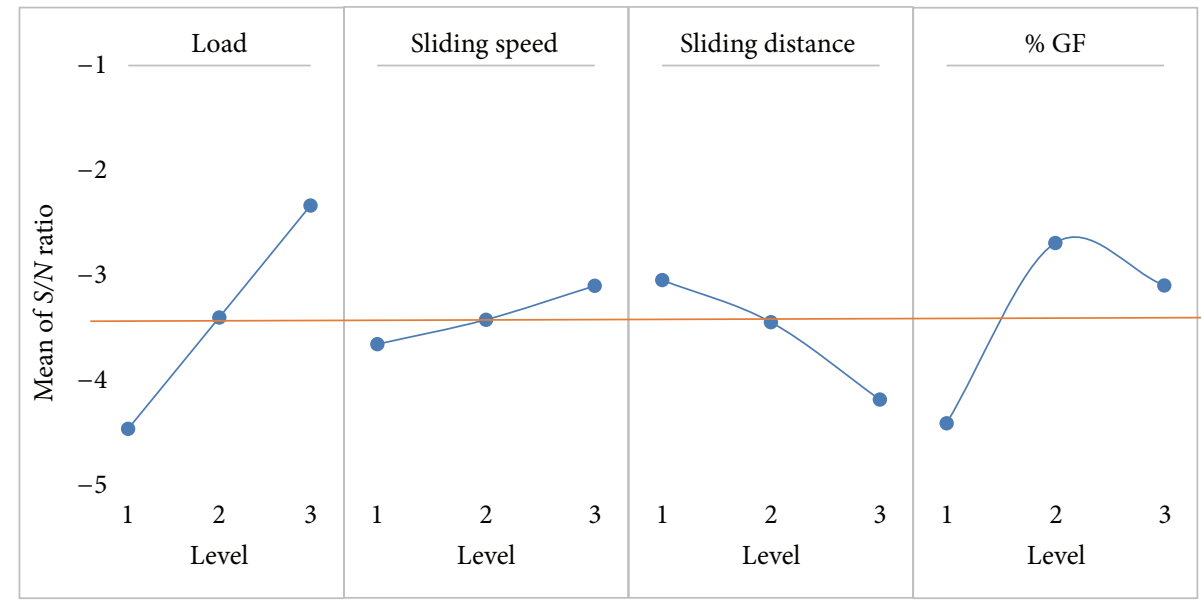

$S / N$ ratio, larger is better

Figure 3: Plot of $S / N$ ratio. 
TABLE 5: Calculated grey relational coefficient of all responses and grey relational grade with weightage.

\begin{tabular}{|c|c|c|c|}
\hline \multirow{4}{*}{ Number of experiment } & \multicolumn{3}{|c|}{ Weighting factor } \\
\hline & 0.5 & 0.5 & Total $=1$ \\
\hline & \multicolumn{2}{|c|}{ Grey relational coefficient } & \multirow{2}{*}{ Overall grey relational grade } \\
\hline & Wear & $\mathrm{COF}$ & \\
\hline 1 & 0.6548 & 0.4983 & 0.5765 \\
\hline 2 & 0.8541 & 0.4410 & 0.6475 \\
\hline 3 & 0.9161 & 0.3333 & 0.6247 \\
\hline 4 & 0.9146 & 0.4378 & 0.6762 \\
\hline 5 & 1.0000 & 0.3517 & 0.6759 \\
\hline 6 & 0.4324 & 0.4536 & 0.4430 \\
\hline 7 & 0.8628 & 0.3607 & 0.6118 \\
\hline 8 & 0.6305 & 0.4587 & 0.5446 \\
\hline 9 & 0.8510 & 0.4174 & 0.6342 \\
\hline 10 & 0.9472 & 0.5891 & 0.7681 \\
\hline 11 & 0.9315 & 0.4433 & 0.6874 \\
\hline 12 & 0.3333 & 0.6725 & 0.5029 \\
\hline 13 & 0.9994 & 0.4576 & 0.7285 \\
\hline 14 & 0.4857 & 0.7792 & 0.6325 \\
\hline 15 & 0.7766 & 0.5527 & 0.6646 \\
\hline 16 & 0.7309 & 0.6498 & 0.6904 \\
\hline 17 & 0.9142 & 0.5750 & 0.7446 \\
\hline 18 & 0.9956 & 0.4353 & 0.7155 \\
\hline 19 & 0.9526 & 0.6255 & 0.7890 \\
\hline 20 & 0.3645 & 0.9344 & 0.6494 \\
\hline 21 & 0.6201 & 0.8179 & 0.7190 \\
\hline 22 & 0.5498 & 1.0000 & 0.7749 \\
\hline 23 & 0.8443 & 0.8677 & 0.8560 \\
\hline 24 & 0.8290 & 0.5846 & 0.7068 \\
\hline 25 & 0.9932 & 0.9247 & 0.9589 \\
\hline 26 & 0.9787 & 0.6096 & 0.7942 \\
\hline 27 & 0.4697 & 0.8995 & 0.6846 \\
\hline
\end{tabular}

TABLE 6: Response for the signal-to-noise $(S / N)$ ratio.

\begin{tabular}{lcccc}
\hline Level & $A$ & $B$ & $C$ & $D$ \\
\hline 1 & -4.447 & -3.648 & -2.817 & -4.395 \\
2 & -3.387 & -3.415 & -3.262 & -2.679 \\
3 & -2.323 & -3.094 & -4.079 & -3.083 \\
Delta & 2.123 & 0.554 & 1.262 & 1.716 \\
Rank & 1 & 4 & 3 & 2 \\
\hline
\end{tabular}

The total mean $S / N$ ratio $\left(\gamma_{i}\right)=-6.84217$.

design factors that affect the output responses. Following (7), initial parameter combination of A1B1C1D1 had been chosen as it lies at the initial level. Again, an actual experiment was conducted with this combination and the value of $\widehat{\gamma}$ thus obtained was also shown in Table 7 . It had been observed that the increase in the $S / N$ ratio from the initial parameter combination to the optimal parameters was -4.78338

From Figure 2, optimum process parameter was selected to be $\mathrm{A} 3 \mathrm{~B} 3 \mathrm{C} 1 \mathrm{D} 2$ which is also the same as Experiment number 25 (load $3 \mathrm{~kg}$, sliding speed $5.1836 \mathrm{~m} / \mathrm{sec}$ (900 rpm), sliding distance $2 \mathrm{~km}$, and $15 \%$ of GF). An estimated value of $\widehat{\gamma}$, corresponding to Experiment number 25, was obtained as -0.7560 and grey relational grade as 0.9166 . Confirmation experimentation was carried out on optimum parameter whose results are shown in Table 7.

\section{Conclusions}

The experiments are carried out on the four inputs, namely, load $(A)$, speed $(B)$, sliding distance $(C)$, and mixtures of glass fiber $(D)$, to find the optimum value for the two responses wear and coefficient of friction. As the responses are opposite in nature, we have used grey relational method, which converts both responses into single response.

Grey relational-Taguchi analysis concludes that optimum response wear and coefficient of friction are found to be load $3 \mathrm{Kg}$, sliding speed $5.1836 \mathrm{~m} / \mathrm{s}$, sliding distance $2 \mathrm{~km}$, and glass fiber 15\% (Experiment number 25). 
TABLE 7: Results of confirmation test.

\begin{tabular}{lccc}
\hline & Initial parameter combination & Optimal parameter combination \\
& AlB1C1D1 & Level & A3B3C1D2 \\
& & Prediction & -0.8722 \\
$S / N$ ratio & -6.4223 & -0.756 & 40.2 \\
Wear $(\mu)$ & 226.24 & & 0.23 \\
COF & 0.33 & 0.9166 & 0.9045 \\
Grey relational grade & 0.4774 & & 0.23 \\
\hline
\end{tabular}

As the percentage of glass fiber in the PTFE increases, its coefficient of friction is increasing and hence $15 \%$ of glass fiber shows the optimum result rather than $20 \%$ of glass fiber.

\section{Competing Interests}

The authors of the paper do not have a direct financial relation with the commercial identity mentioned in their paper that might lead to competing interests for any of the authors.

\section{References}

[1] K. Tanaka, Y. Uchiyama, and S. Toyooka, "The mechanism of wear of polytetrafluoroethylene," Wear, vol. 23, no. 2, pp. 153172, 1973.

[2] L. L. Wang, L. Q. Zhang, and M. Tian, "Mechanical and tribological properties of acrylonitrile-butadiene rubber filled with graphite and carbon black," Materials and Design, vol. 39, pp. 450-457, 2012.

[3] L. Chang, Z. Zhang, L. Ye, and K. Friedrich, “Tribological properties of high temperature resistant polymer composites with fine particles," Tribology International, vol. 40, no. 7, pp. 1170-1178, 2007.

[4] Y.-K. Yang, “Optimization of injection-molding process for mechanical and tribological properties of short glass fiber and polytetrafluoroethylene reinforced polycarbonate composites with grey relational analysis: a case study," Polymer-Plastics Technology and Engineering, vol. 45, no. 7, pp. 769-777, 2006.

[5] M. H. Cho, S. Bahadur, and A. K. Pogosian, "Friction and wear studies using Taguchi method on polyphenylene sulfide filled with a complex mixture of $\mathrm{MoS}_{2}, \mathrm{Al}_{2} \mathrm{O}_{3}$, and other compounds," Wear, vol. 258, no. 11-12, pp. 1825-1835, 2005.

[6] D. Xiang and C. Gu, "A study on the friction and wear behavior of PTFE filled with ultra-fine kaolin particulates," Materials Letters, vol. 60, no. 5, pp. 689-692, 2006.

[7] T. J. Ridson and R. D. Loban, "Effect of molybdenum di-sulfide on the wear rates of polymer composites," in Proceedings of the ASLE Proceedings of the 2nd International Conference on Solid Lubrication, pp. 230-236, Denver, Colo, USA, August 1978.

[8] K. Tanaka and S. Kawakami, "Effect of various fillers on the friction and wear of polytetrafluoroethylene-based composites," Wear, vol. 79, no. 2, pp. 221-234, 1982.

[9] A. Golchin, G. F. Simmons, and S. B. Glavatskih, "Break-away friction of PTFE materials in lubricated conditions," Tribology International, vol. 48, pp. 54-62, 2012.

[10] S. Basavarajappa, G. Chandramohan, and J. Paulo Davim, "Application of Taguchi techniques to study dry sliding wear behaviour of metal matrix composites," Materials and Design, vol. 28, no. 4, pp. 1393-1398, 2007.

[11] M. Conte and A. Igartua, "Study of PTFE composites tribological behavior," Wear, vol. 296, pp. 568-574, 2012.

[12] M. Onan, K. Baynal, and H. İ. Ünal, "Determining the influence of process parameters on the induction hardening of AISI 1040 steel by an experimental design method," Indian Journal of Engineering and Materials Sciences, vol. 22, no. 5, pp. 513-520, 2015.

[13] G. Taguchi, Introduction to Quality Engineering, Asian Productivity Organization, Tokyo, Japan, 1990.

[14] D. C. Montgomery, Design and Analysis of Experiments, John Wiley \& Sons, New York, NY, USA, 5th edition, 2006.

[15] S. Bahadur and D. Tabor, "Role of fillers in the friction and wear behavior of high-density polyethylene," Polymer Wear and Its Control, vol. 287, pp. 253-268, 1985.

[16] S. Biswas and A. Satapathy, "Tribo-performance analysis of red mud filled glass-epoxy composites using Taguchi experimental design," Materials and Design, vol. 30, no. 8, pp. 2841-2853, 2009.

[17] Y. S. Tarng, S. C. Juang, and C. H. Chang, "The use of grey-based Taguchi methods to determine submerged arc welding process parameters in hardfacing," Journal of Materials Processing Technology, vol. 128, no. 1-3, pp. 1-6, 2002.

[18] A. K. Sood, R. K. Ohdar, and S. S. Mahapatra, "Improving dimensional accuracy of fused deposition modelling processed part using grey Taguchi method," Materials and Design, vol. 30, no. 10, pp. 4243-4252, 2009.

[19] Y. Kuo, T. Yang, and G.-W. Huang, “The use of a grey-based Taguchi method for optimizing multi-response simulation problems," Engineering Optimization, vol. 40, no. 6, pp. 517-528, 2008.

[20] C. R. Hick, Fundamental Concepts in the Design of Experiments, Oxford University Press, Oxford, UK, 5th edition, 1999. 

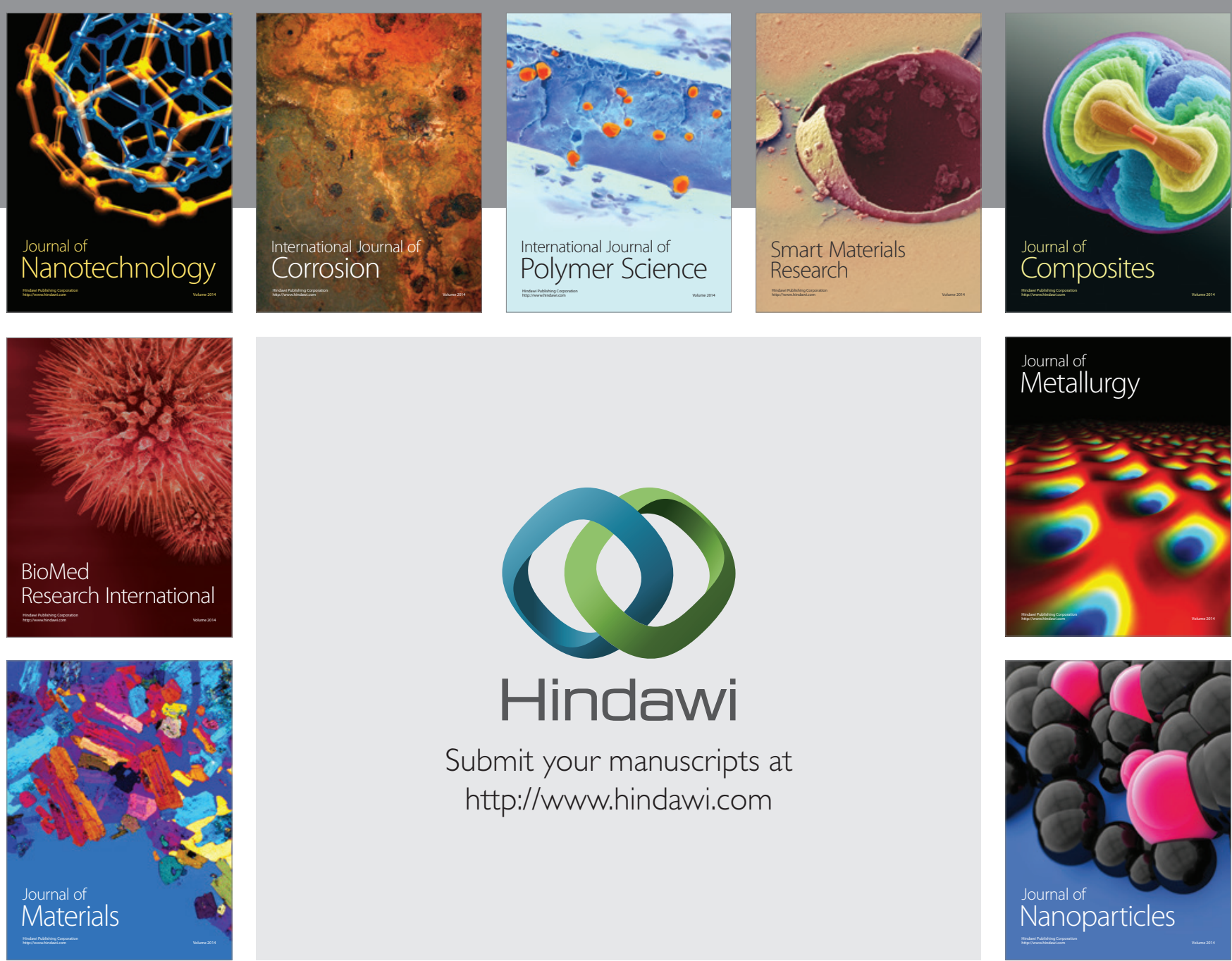

\section{Hindawi}

Submit your manuscripts at

http://www.hindawi.com

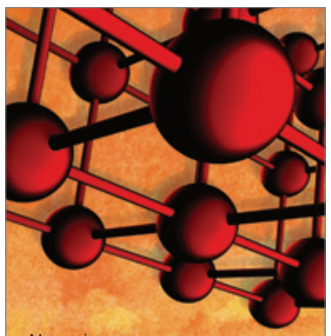

Materials Science and Engineering
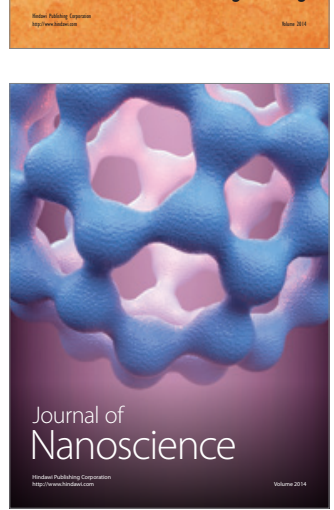
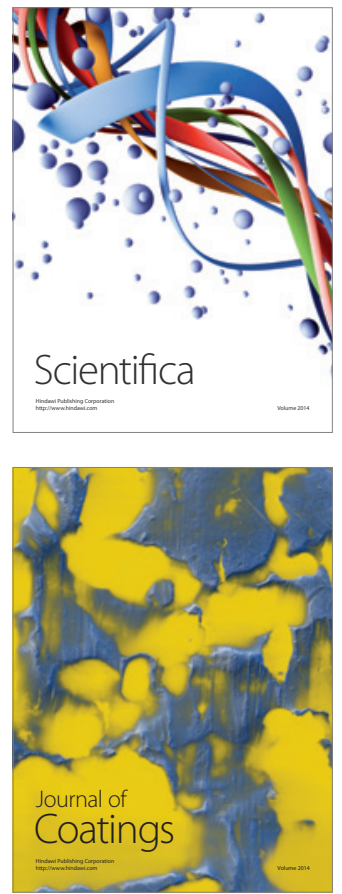
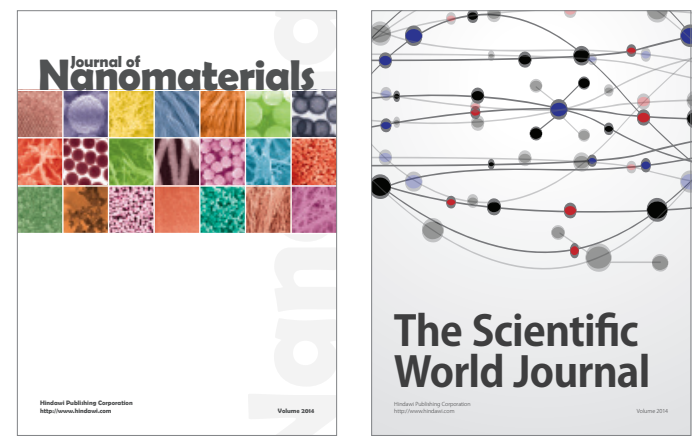

The Scientific World Journal
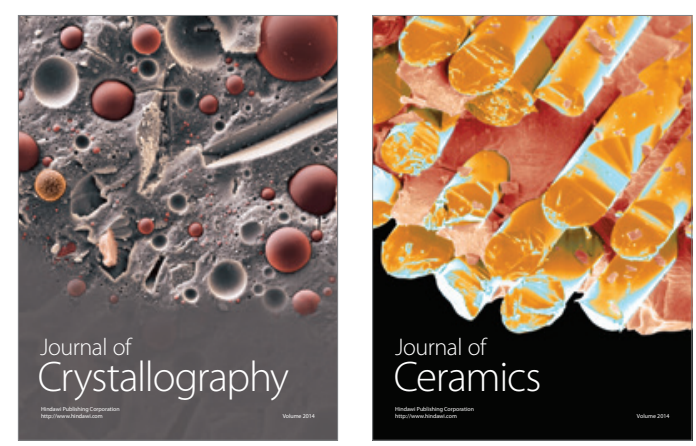
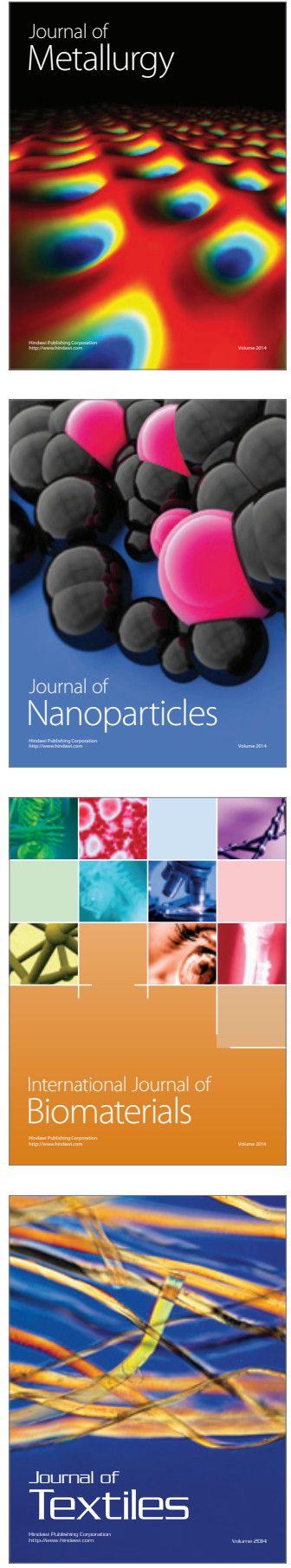